\title{
ALGUNAS CONSIDERACIONES GEOGRÁFICAS SOBRE LOS PRINCIPIOS AMBIENTALES DE LA LEY 6/1994, REGULADORA DE LA ACTIVIDAD URBANÍSTICA VALENCIANA ${ }^{1}$
}

\author{
José Manuel Giménez Ferrer \\ Instituto Universitario de Geografía \\ Universidad de Alicante
}

\begin{abstract}
RESUMEN
La legislación urbanística valenciana es, a todas luces, un marco operativo infrautilizado en cuanto a sus ingentes potencialidades como herramienta de ordenación sostenible del suelo municipal. Su posición jerárquica, como eslabón pionero, sobre el que descansan gran parte de los efectos negativos que la ocupación antrópica del territorio lleva consigo, le otorga una trascendental virtuosidad a la hora de subsanar desmanes pretéritos y evitar futuros impactos perjudiciales. La potestad de elevar al grado de vinculantes los estudios territoriales inherentes a la ejecución del planeamiento, constituye una herramienta de ordenación del territorio de tan magna potencialidad, como enorme es su desuso y sin parangón su desconocimiento.
\end{abstract}

Palabras clave: legislación del suelo, ordenación del territorio, sostenibilidad, estudios geográficos del medio y aptitud territorial.

\section{ABSTRACT}

Town-planning legislation in the Valencian Region is (evidently) an action framework under-used despite of its potencialities as a sustainable planning tool. Its main hie-

\footnotetext{
* Tras las elecciones de mayo de 2003, y a los efectos que interesan en el presente artículo, la Conselleria d'Obres Públiques, Urbanisme i Transports de la Generalitat Valenciana (COPUT) ha dejado de existir como tal, ubicándose sus competencias en el seno de dos nuevas consellerias, tras la aprobación del actual organigrama administrativo autonómico: por un lado, la de «Territori i Habitatge» y, por el otro, la «d'Infraestructures i Transports». Es la primera de ellas la que asume la mayor parte de las competencias en materia de urbanismo y ordenación territorial siendo, en consecuencia, la aludida a todos los efectos.

1 El presente artículo forma parte de la Memoria de Licenciatura «La consideración del riesgo de inundación en el planeamiento urbano: el litoral meridional alicantino (El Pilar de la Horadada y Orihuela)», defendida en julio de 2002 bajo la dirección de D. Jorge Olcina Cantos y realizada en el seno del Laboratorio de Climatología del Instituto Universitario de Geografía de la Universidad de Alicante; todo ello en el marco del Proyecto de Investigación Aguaceros de gran intensidad horaria, aguaduchos e inundaciones en áreas urbanas de las tierras alicantinas (1998-2001) dirigido por D. Antonio Gil Olcina.
} 
rarchic position in the legal structure relate to land uses gives an essential role to townplanning legislation in correcting past mistakes and in avoiding negative impacts in the future. The option to make compulsory for human activities and land uses the results of the environmental studies connected with planning is a vigorous tool for land planning, paradoxically unknown and under-used.

Key words: town-planning legislation, land planning, sustainability, environmental studies, land aptitude.

\section{El sistema urbanístico valenciano: marco competencial y disposiciones legales de aplicación}

El fundamento operativo de la materia urbanística como competencia autonómica ${ }^{2}$ encuentra su soporte en el artículo $148.1 .3^{\circ}$ de la Constitución Española de 1978 (en adelante, CE) al enumerar a la compleja materia ordenación del territorio, urbanismo y vivien$d a$ entre aquellas respecto a las cuales todas las comunidades autónomas pueden asumir competencias exclusivas o plenas, lo cual queda ampliamente mediatizado por el importante carácter concurrente que dicha materia presenta desde un punto de vista eminentemente competencial. El Estatuto de Autonomía de la Comunidad Valenciana aprobado por Ley Orgánica 5/1982, de 1 de julio, opera como norma fundamental del entero cuerpo legislativo valenciano y, en tal calidad, como norma-gozne capaz de actuar simultáneamente como cabecera del grupo normativo autonómico y organizadora de la relación y articulación de éste con el cuerpo normativo estatal (PAREJO ALONSO y BLANC CLAVERO, 1999; 27). Es el punto noveno del artículo 31 de dicho Estatuto donde la Generalitat asume plenamente la competencia desprendida por el artículo $148.1 .3^{\circ}$ de la Carta Magna Española en términos de exclusiva, es decir, plena sobre la materia urbanística y acaparando con ello las funciones constitucionales legislativas y ejecutivas sobre la misma. Pero el descanso de dicho carácter competencial pleno sobre la administración autonómica no es óbice para que ésta olvide el carácter concurrente que ella presenta con otras competencias constitucionalmente atribuidas a la Administración General del Estado.

El sustrato geográfico sobre el que se asientan las determinaciones urbanísticas, el cual constituye el soporte físico de las mismas, hace que sea ésta una materia del ordenamiento jurídico sometida a un siempre latente problema competencial; en tanto y cuanto su objeto regulado (el suelo) puede ser afectado por muy diversas actuaciones administrativas (parte

2 Las competencias del Estado y de las Comunidades Autónomas sobre las distintas materias del ordenamiento jurídico español pueden ser:

- Competencias Exclusivas: las que corresponden plenamente, en sus manifestaciones legislativa básica, de desarrollo, reglamentaria y de ejecución, a una sola administración (Central, Autonómica o Local).

- Competencias Compartidas: aquéllas que se atribuyen en parte a una administración y en parte a otra. Por lo general es el Estado el que se encarga de determinar el régimen básico; mientras que el desarrollo y la ejecución, o sólo esta última, recae en la competencia autonómica. Ejemplo de dicho reparto competencial lo es el medio ambiente como objeto de regulación jurídica.

- Competencias Concurrentes: atribuidas a una administración y recayendo sobre un objeto jurídico concreto, entran en contacto, relación o colisión, con otras materias propias de otra administración que afectan a una materia distinta pero próxima al de aquellas. La competencia urbanística es un claro ejemplo de dicha estructura organizativa. 
de una calzada de una vía de Interés General del Estado, de una repoblación forestal, puede estar ubicado en las cercanías de un curso fluvial, en el seno de un complejo militar,...). Así, los posibles conflictos competenciales que pueden surgir entre los distintos niveles territoriales mediante los cuales se organiza administrativamente el Estado Español tienen especial relevancia en el ámbito urbanístico, ya que sobre cada metro cuadrado de suelo ejercen (o pueden hacerlo) sus competencias administrativas el Municipio y la Provincia (entes locales), las Comunidades Autónomas, el Estado y, en última instancia y cada vez con más fuerza, la Unión Europea. En este sentido, sobre el territorio existe un tipo de competencia material horizontal, de titularidad, fundamentalmente, de un determinado órgano administrativo, el cual es el encargado de encauzar legislativamente el cuerpo normativo de la materia. En el caso del urbanismo, su definición competencial horizontal es compleja, ya que, a pesar de que la constitución otorga la competencia exclusiva y plena a la administración autonómica, la incidencia estatal en la misma con otros títulos constitucionales no estrictamente urbanísticos es manifiesta, con lo que volvemos al carácter concurrente de la materia como garante máximo de la comprensión competencial que subyace a la misma en el actual Estado de las Autonomías.

La complejidad que todo ello supone hace del principio de colaboración interadministrativa un presupuesto básico y de trascendente aplicación, cuyo fundamento operativo queda magníficamente recogido en el punto sexto de la Exposición de Motivos de la modificada Ley 30/1992, de 26 de noviembre, de Régimen Jurídico de las Administraciones Públicas y del Procedimiento Administrativo Común ${ }^{3}$ :

«...es condición inexcusable para articular el ordenado desenvolvimiento de la actividad administrativa desde el momento en que coexisten una diversidad de Administraciones que proyectan su actividad sobre el mismo ámbito territorial, personal y, en ocasiones, material, actividad que a la vez debe cumplir criterios de eficacia sin menoscabo de competencias ajenas. Conjugar esta pluralidad de factores obliga intensificar las relaciones de cooperación, mediante la asistencia recíproca, el intercambio de información, las conferencias sectoriales para la adopción de criterios y puntos de vista comunes al abordar los problemas de cada sector, o la celebración de convenios de colaboración, con aspectos generales que podrán ser susceptibles de concreción en los distintos sectores de la actividad administrativa».

El encuadre competencial horizontal del urbanismo queda muy bien explicitado en los distintos Fundamentos Jurídicos mediante los cuales el Alto Tribunal articula su Sentencia 61/1997, de 20 de marzo, con motivo del fallo a los distintos recursos de inconstitucionalidad que recayeron sobre la legislación del suelo estatal refundida a partir del texto legal

3 Las implicaciones geográficas resultantes del desconocimiento del complejo sistema competencial inherente a la práctica urbanística son muy elevadas. El geógrafo, como investigador territorial, ha de saber analizar los problemas en su justo contexto, siendo el aspecto competencial un auténtico ejercicio de síntesis operativa que todo buen geógrafo ha de saber encauzar. Determinar el grado de afecciones existentes en todo proyecto urbanístico, las administraciones involucradas y las implicaciones territoriales propias que un acertado ejercicio racional ha de saber sopesar, en tanto y cuanto sobre la base de éstas se pueden determinar aspectos de tan marcado cariz geográfico como el análisis de los peligros naturales y de los impactos ambientales, son bazas del saber geográfico relacionadas con la materia urbanística de magna trascendencia en la correcta (y por qué no, sostenible) definición de todo modelo de desarrollo local. 
Cuadro 1

REPARTO COMPETENCIAL ENTRE ESTADO Y COMUNIDADES AUTÓNOMAS EN DISTINTAS MATERIAS DE CLARA INCIDENCIA EN LA PRÁCTICA URBANÍSTICA

\begin{tabular}{|c|c|c|}
\hline Materia & Competencia & Normativa \\
\hline Urbanismo & CCAA & Art. 148.1.3 ${ }^{\mathrm{a}} \mathrm{CE} /$ Estatutos de Autonomía \\
\hline Ordenación Territorial & CCAA & Art. 148.1.3 ${ }^{\mathrm{a}} \mathrm{CE}$ / Estatutos de Autonomía \\
\hline Vivienda & CCAA & Art. 148.1.3 ${ }^{\mathrm{a}} \mathrm{CE}$ / Estatutos de Autonomía \\
\hline Agricultura & CCAA & Art. $148.1 .7^{\circ} \mathrm{CE} /$ Estatutos de Autonomía \\
\hline Legislación Civil (derechos de propiedad) & ESTADO & Art. $149.1 .8^{\circ} \mathrm{CE}$ \\
\hline $\begin{array}{l}\text { Ordenación de los Registros e instrumentos } \\
\text { públicos }\end{array}$ & ESTADO & Art. $149.1 .8^{\circ} \mathrm{CE}$ \\
\hline $\begin{array}{l}\text { Tratamiento fiscal de la propiedad } \\
\text { inmobiliaria y de las operaciones urbanísticas }\end{array}$ & ESTADO & Art. $149.1 .14^{\circ} \mathrm{CE}$ \\
\hline Legislación sobre Expropiación Forzosa & ESTADO & Art. $149.1 .18^{\circ} \mathrm{CE}$ \\
\hline Puertos y aeropuertos de interés general & ESTADO & Art. $149.1 .20^{\circ} \mathrm{CE}$ \\
\hline Ferrocarriles & ESTADO & Art. $149.1 .21^{\circ} \mathrm{CE}$ \\
\hline $\begin{array}{l}\text { Legislación básica sobre medio ambiente, } \\
\text { montes, aprovechamientos forestales } \\
\text { y vías pecuarias }\end{array}$ & $\begin{array}{l}\text { COMPARTIDA y } \\
\text { CONCURRENTE }\end{array}$ & Art. $149.1 .23^{\circ} \mathrm{CE}$ \\
\hline $\begin{array}{l}\text { Obras Públicas de interés general o cuya } \\
\text { realización afecte a más de una }\end{array}$ & & \\
\hline Comunidad Autónoma & ESTADO & Art. $149.1 .24^{\circ} \mathrm{CE}$ \\
\hline $\begin{array}{l}\text { Bases y coordinación de la planificación } \\
\text { general de la actividad económica }\end{array}$ & ESTADO & Art. $149.1 .13^{\circ} \mathrm{CE}$ \\
\hline
\end{tabular}

FUENTE: Constitución Española de 1978. Elaboración propia.

8/1990, de 25 de julio. El Constitucional es tajante al deslindar la competencia urbanística de carácter más administrativa y propia de la autoridad regional (ordenación, planeamiento, gestión, ejecución y disciplina) de las estrictamente relacionadas con el estatuto jurídico del suelo, cuya regulación es exclusivamente estatal (artículo 149.1.1 ${ }^{\circ}$. de la CE). Reconoce sobre la primera una capacidad normativa plena de las Comunidades Autónomas, negando cualquier intrusión al respecto del Estado; mientras que sobre las segundas concluye que este último ostenta competencia para fijar las condiciones básicas que garanticen la igualdad en el ejercicio de los derechos y deberes de los propietarios de suelo en todo el territorio Nacional, sin que ello pueda interpretarse como el establecimiento de un régimen homogéneo de ordenación para toda España.

Consecuentemente, en la actualidad son dos los cuerpos normativos, de carácter puramente urbanístico, que han de contemplarse en todo análisis geográfico de la legislación del suelo en un determinado ámbito regional, en este caso, la Comunidad Valenciana. El primero de ellos lo dicta el carácter concurrente propio del ejercicio competencial en la materia, donde la legislación Estatal sobre régimen de suelo y valoraciones juega un papel predominante, enmarcado en la Ley 6/1998, de 13 de abril, sobre régimen de suelo y valoraciones; el Real Decreto Legislativo 4/2000 de 23 de junio y la Sentencia del Tribunal 
Cuadro 2

ÁMBITOS DE LA COMPETENCIA URBANÍSTICA SOBRE LA QUE INCIDEN DISTINTOS TÍTULOS COMPETENCIALES

\begin{tabular}{|c|c|}
\hline Funciones & Órgano competente \\
\hline \multicolumn{2}{|l|}{ Planeamiento } \\
\hline Redactar el Plan General de Ordenación & CCAA/Entidades Locales \\
\hline Emplazar centros de producción y residencia & ESTADO / CCAA \\
\hline Clasificar suelo municipal & CCAA / Entidades Locales \\
\hline Calificar suelo municipal & CCAA / Entidades Locales \\
\hline Formular el trazado de vías públicas y medios de comunicación & ESTADO / CCAA / Entidades Locales \\
\hline $\begin{array}{l}\text { Orientar la composición arquitectónica de los edificios y otras } \\
\text { condiciones estéticas }\end{array}$ & Entidades Locales \\
\hline \multicolumn{2}{|l|}{ Régimen de Suelo } \\
\hline $\begin{array}{l}\text { Procurar el uso del suelo en consonancia con la utilidad } \\
\text { pública y la función social de la propiedad }\end{array}$ & ESTADO \\
\hline $\begin{array}{l}\text { Imponer la justa distribución de beneficios y cargas del } \\
\text { planeamiento }\end{array}$ & ESTADO \\
\hline Regular el mercado del suelo & ESTADO \\
\hline Garantizar el uso racional del suelo & ESTADO / CCAA / Entidades Locales \\
\hline Configurar patrimonios municipales de suelo & Entidades Locales \\
\hline \multicolumn{2}{|l|}{ Ejecución de la urbanización } \\
\hline Encauzar, dirigir, fiscalizar y conceder obras de urbanización & Entidades locales \\
\hline $\begin{array}{l}\text { Expropiar terrenos y construcciones necesarios para la } \\
\text { ejecución de las obras }\end{array}$ & Entidades locales \\
\hline \multicolumn{2}{|l|}{ Uso del suelo y edificación } \\
\hline Ceder terrenos edificables y derechos reales sobre los mismos & Entidades locales \\
\hline Intervenir la parcelación & Entidades locales \\
\hline $\begin{array}{l}\text { Exigir a los propietarios/urbanizadores que edifiquen en plazos } \\
\text { determinados }\end{array}$ & Entidades locales \\
\hline Imponer la venta forzosa cuando no se edifique en tiempo y forma & Entidades locales \\
\hline Prohibir los usos no ajustados a los estipulado en el planeamiento & Entidades locales \\
\hline Intervenir en la construcción y uso de las fincas & Entidades locales \\
\hline $\begin{array}{l}\text { Proponer la posibilidad de facilitar los medios precisos a los } \\
\text { titulares para cumplir los dispuesto en la Ley }\end{array}$ & ESTADO / CCAA / Entidades Locales \\
\hline
\end{tabular}

FUENTE: MELÓN MUÑOZ (1999). Elaboración propia.

Constitucional 167/2001. En el seno de este marco operativo se encuentra la regulación estatal de los distintos criterios que definen las categorías de suelo a establecer por el planeamiento municipal, aspecto éste esencial que han de asumir las distintas regulaciones autonómicas en la materia y cuyas implicaciones geográficas son, a todas luces, trascendentales y, a su vez, limitativas, en tanto que reducen la capacidad de maniobra autonómica y, más concretamente, local, a la hora de establecer un determinado modelo de 
desarrollo urbano municipal. Bajo los auspicios de las determinaciones estatales en la materia, la Generalitat crea su propio cuerpo normativo al efecto encargado de establecer los principios urbanísticos garantes de sus justas y constitucionales aspiraciones autonómicas de desarrollo urbano.

\section{Cuadro 3}

\section{NORMATIVA URBANÍSTICA ESTATAL Y AUTONÓMICA DE DIRECTA APLICACIÓN} EN LA COMUNIDAD VALENCIANA

\begin{tabular}{|c|}
\hline al \\
\hline $\begin{array}{l}\text { - Ley } 6 / 1998 \text {, de } 13 \text { de abril, de régimen del suelo y valoraciones (en adelante LS98) } \\
\text { - Real Decreto Ley 4/2000, de } 23 \text { de junio, de medidas urgentes de liberalización del sector inmobiliario y } \\
\text { transportes (en adelante (DL00) } \\
\text { - Sentencia del Tribunal Constitucional 164/2001, de } 11 \text { de julio. }\end{array}$ \\
\hline \\
\hline 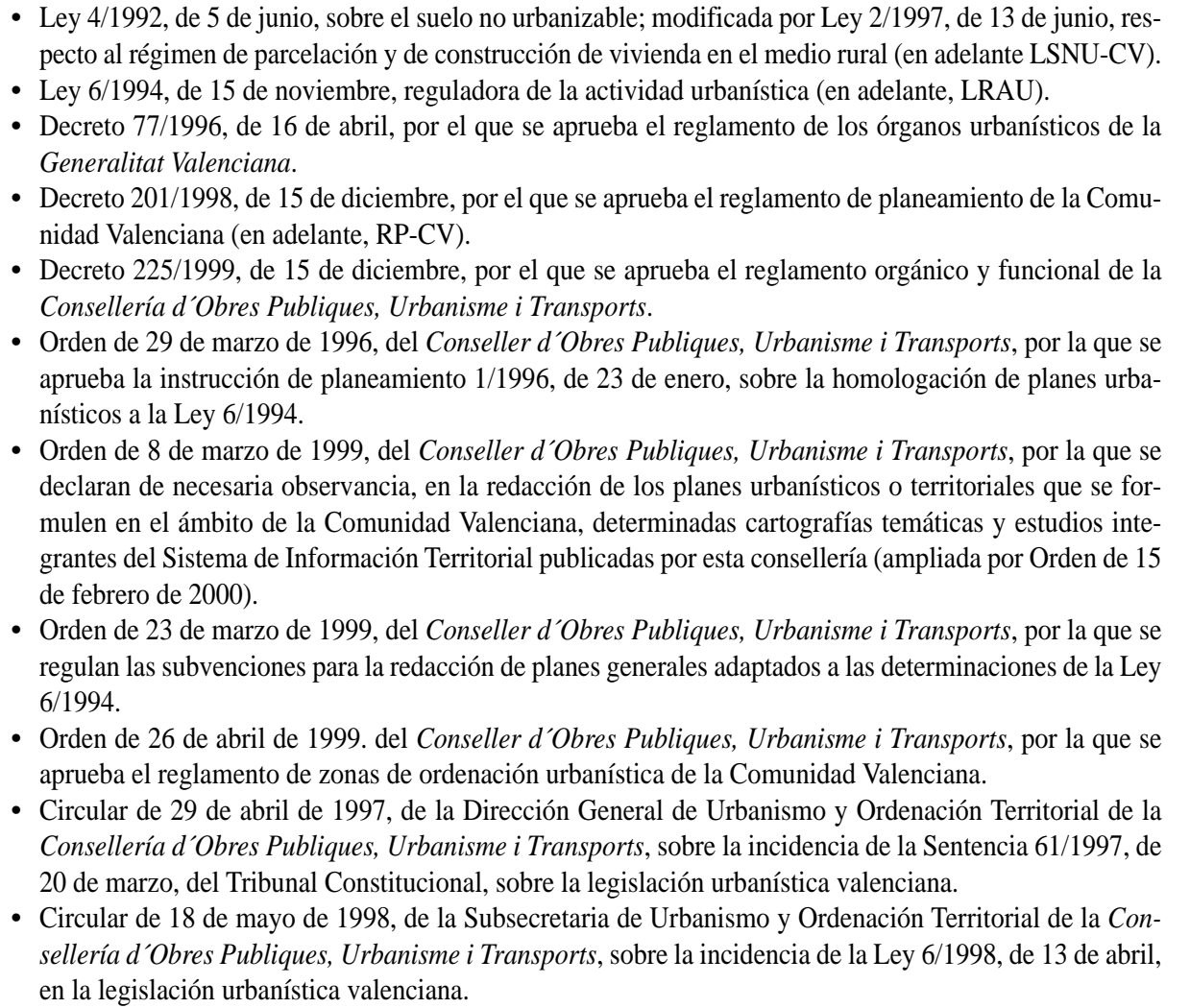 \\
\hline
\end{tabular}

Elaboración propia. Las «circulares» poseen un carácter informativo más que normativo. 


\section{La Ley 6/1994, de 15 de noviembre, de la Generalitat Valenciana, reguladora de la actividad urbanística y su reglamento de desarrollo: la liberalización a ultranza de la práctica urbanística}

\subsection{Principales aportaciones de la LRAU y sus implicaciones territoriales}

Antes de analizar los preceptos más significativos de la ley valenciana en su relación con la práctica ambiental, es interesante detenerse, sucintamente, en los principales objetivos de la citada Ley, sobre todo en lo referente a sus nuevos sistemas de gestión amparados en programas mediante los cuales la administración delega su función urbanística en un nuevo y novedoso agente: el urbanizador.

La nueva Ley comporta un cambio de orientación en objetivos y principios generales respecto a leyes urbanísticas anteriores. La tendencia general de éstas era responsabilizar al propietario de los terrenos de la acción urbanizadora. Los planes programaban los desarrollos urbanísticos y los propietarios quedaban obligados, y facultados a la vez, para su desarrollo. Por eso las leyes distinguían entre sistemas de actuación públicos (a cargo de la administración: cooperación y expropiación) y sistemas de actuación privados (a cargo del propietario: compensación). En la LRAU la responsabilidad de urbanizar es siempre pública, pudiendo participar también los propietarios en dicho proceso, pero cambiando sustancialmente las fórmulas en las que dicha participación se produce. Antes lo podían hacer en calidad de propietarios, en cambio, con la LRAU lo pueden hacer en calidad de agentes urbanizadores que actúan por convenio con la administración municipal. Para convertirse en agente urbanizador no basta con ser dueño de los predios (aunque ello sea una ventaja importante), pudiendo acceder a esa condición empresarios particulares que pueden obtener mediante dicha práctica un efecto lucrativo propio y, por ende, para la comunidad, al ofrecer suelo urbanizado a la acción inmobiliaria.

En materia de planeamiento urbanístico, los instrumentos de la LRAU son muy similares a los imperantes en la legislación estatal precedente, sin exigir ésta una adaptación inmediata a sus disposiciones por el planeamiento vigente a la entrada en vigor de la misma (para ello se establece un procedimiento intermedio, la homologación). Los planes urbanísticos que la LRAU contempla son los siguientes:

- Planes de Acción Territorial de Finalidad Urbanística: instrumentos de ordenación del territorio cuyo cometido es coordinar los distintos planeamientos municipales entre sí, estableciendo directrices que sirvan de marco de referencia para el planeamiento municipal respecto a las previsiones de la administración sectorial y supramunicipal. Estos planes de acción territorial pueden ser de distinta temática, abordando una determinada problemática sobre un espacio concreto que ha ser observada por el planeamiento (ejemplo claro de ello es el recientemente aprobado plan de acción territorial contra el riesgo de inundación).

- Planes Generales: desaparecen las normas subsidiarias y las delimitaciones de suelo urbano como documentos de planeamiento general, debiendo contar todos los municipios con plan general, aunque cuanto menor tamaño y menor problemática urbanística tenga el mismo, ganará en sencillez la documentación a incorporar. Lo más importante del planeamiento general que auspicia la LRAU es que ha de cumplir un doble cometido, articulándose en dos tipos de determinaciones fundamentales: 
- Para todo el término municipal contendrá lo que la Ley llama ordenación estructural, la cual es la encargada de definir el modelo territorial seleccionado. Ésta está formada por las directrices definitorias de la estrategia de evolución urbana, la clasificación del suelo, la división del territorio en zonas de ordenación, la ordenación del suelo no urbanizable, la delimitación de sectores, el tratamiento, conforme a su legislación reguladora, de los bienes de dominio público no municipal, el establecimiento de áreas de reparto y del aprovechamiento tipo, la expresión de los objetivos a considerar en la redacción de los instrumentos de desarrollo del plan general, la ordenación de los centros cívicos y de las actividades susceptibles de generar tráfico intenso y la delimitación de una red primaria, o estructural, de reserva de terrenos y construcciones de destino dotacional público que asegure la racionalidad y coherencia del desarrollo urbanístico.

- Para todo o parte del suelo urbano y urbanizable, el plan deberá contener una ordenación pormenorizada que facilite su posterior gestión por el planeamiento de desarrollo

- Planes parciales: contenido muy similar al establecido en la legislación estatal, con la salvedad de que la LRAU permite que éstos puedan alterar las determinaciones del plan general, siempre que respeten las directrices generales de su modelo territorial definidas mediante la ordenación estructural.

- Planes de reforma interior: cumplen la misma función que los planes parciales, pero en vez de afectar a zonas no desarrolladas urbanísticamente, afectan a núcleos de población consolidados o urbanizados. También se contempla la posibilidad de que contengan alternativas a las disposiciones del plan general.

- Planes especiales: se promueven con la finalidad de plantear otras posibilidades a las previsiones urbanísticas cuando ello se estime oportuno para la mejor eficacia del planeamiento.

Con respecto a la clasificación del suelo la LRAU muestra con exactitud su más que evidente orientación hacia su ya cada vez más consolidada concepción como ley de gestión urbanística por antonomasia, ya que el criterio para la clasificación de suelo en el plan general como urbano, urbanizable y no urbanizable está muy relacionado con dicha finalidad (sobre todo en el caso de los dos primeros). Se parte de la previa delimitación del no urbanizable de acuerdo con los criterios establecidos por la LSNU-CV, en virtud de los cuales se delinean los sectores que serán excluidos de actuaciones urbanísticas integrales, es decir, de transformaciones que lleven implícita la parcelación de terrenos (salvo el caso de la declaración de interés comunitario extraordinaria con regulación propia al efecto), ya sea por su protección mediante legislación sectorial específica, por su protección por el planeamiento general o, en última instancia, por no ser considerados aptos para del desarrollo urbanístico planeado por el municipio ${ }^{4}$. Por otro lado, el suelo urbano será clasificado como aquél que se pueda ejecutar urbanísticamente sin la necesidad de limitar unidades de ejecución ni grandes proyectos de obra pública que sirvan de soporte para el desarrollo de aquellas; desapareciendo la tradicional concepción de la legislación estatal que asociaba el suelo

4 Conviene advertir que este último supuesto ha sido derogado por el DL4/2000, mediante el cual la suspensión del suelo no urbanizable común como categoría obliga a que todo lo que no tenga un valor territorial demostrable haya de ser clasificado como urbanizable de forma automática. La influencia de ello en el modelo territorial municipal y en la protección del suelo es más que evidente. 
urbano a la concurrencia de una serie de servicios más relacionados con la definición de solar que con la estricta delimitación de un ámbito de planeamiento con gestión diferenciada. Finalmente, el suelo urbanizable es el que, por imperativo del plan, se debe ejecutar o desarrollar urbanísticamente mediante la delimitación de distintas unidades de ejecución, las cuales si comportan importantes proyectos de obra pública.

Además de los instrumentos clásicos y tradicionales de planeamiento, cabe destacar la aparición de la cédula de urbanización en el sistema urbanístico valenciano, la cual es concebida por la Ley como un instrumento de coordinación entre el ejercicio de las competencias municipales en materia de planeamiento con el de las competencias urbanísticas y sectoriales del resto de las administraciones. Así, instrumento que aboga por la necesaria y ya comentada coordinación administrativa, el cual tiene por objeto evitar que el desarrollo municipal de los planes pueda desconocer, o ser contradictorio, con el ejercicio de las competencias de otras administraciones públicas. Además, también busca esclarecer si las propuestas de planeamiento parcial a desarrollar respetan o no las determinaciones de la ordenación estructural aprobada por la administración urbanística autonómica. Es dicha cédula la que acredita la existencia, o no, de la afección enunciada, por lo que la no necesidad de la misma, es decir, la propuesta de planeamiento parcial que se ajuste a las determinaciones estructurales, sin modificarlas, será aprobada definitivamente por la autoridad municipal, mientras que en caso contrario, necesitará de expedición de la cédula que regulará dicha afección y otras tantas que pudieran derivar del proceso. La cédula puede considerarse un instrumento de control autonómico de la práctica urbanística municipal, ya que con dicho trámite la Generalitat se faculta para revisar la totalidad de los documentos de planeamiento parcial a desarrollar en el seno de su territorio, cotejando sus determinaciones con la ordenación estructural ya aprobada por ella. Pero, como es evidente, ya se ha indicado que le LRAU establecía la determinación de la ordenación estructural como uno de los objetivos esenciales del Plan General, pero para que éste la determine ha de estar adaptado a la nueva Ley, con lo que podría darse el caso de planes generales que no tuvieran delimitada la ordenación estructural de su municipio, con lo que el trámite de la cédula carecía de validez operativa. Para subsanar dicho proceso, ya en el marco conjunto de la gestión y ordenación urbanística, la LRAU estableció el procedimiento de la homologación del planeamiento.

La homologación del planeamiento a la LRAU no debe confundirse con la adaptación a la misma, ya que ésta es concebida como una operación de alcance mucho más limitado. La homologación tiene por objeto discernir y aclarar, en relación con un plan vigente con anterioridad a la LRAU, cuáles de sus determinaciones deben ser propias de la ordenación estructural (tienen por tanto competencia autonómica en su aprobación y supervisión mediante la expedición de cédula si son alteradas o afectadas) y cuáles, por el contrario, tienen el carácter de ordenación pormenorizada. Ésta puede llevarse a cabo de una vez para todo el plan general o para sectores de planeamiento parcial o de reforma interior exclusivamente. Así, el procedimiento de homologación tiene por objeto hacer posible dicha diferenciación en un instrumento de planeamiento general no adaptado a la LRAU. Una vez aprobada la homologación, el sistema de distribución competencial entre la administración autonómica y la local, amparado en la expedición de la cédula como garante final de que el planeamiento se adapta a lo estructuralmente determinado por la Generalitat, entra en juego con plenitud de posibilidades.

Partiendo de la base de que la LRAU es, ante todo, una ley de gestión urbanística, y como ésta se adelantó a la legislación estatal a la hora de eliminar la distinción clasificato- 
ria de suelo entre programado y no programado, la ley valenciana ideó un nuevo instrumento de programación similar a los tradicionales programas de actuación urbanística del suelo urbanizable no programado, ello con el objetivo de planificar la gestión de los distintos sectores en los que se divide el suelo urbanizable. En la LRAU todo el suelo urbanizable es implícitamente no programado hasta que se apruebe para él un programa. Para ello idea los Programas para el desarrollo de Actuaciones Integradas, los cuales son un instrumento de gestión encargado de regular y normativizar el proceso de urbanización del sector, o los sectores, a desarrollar al amparo de las unidades de ejecución incluidas en su ámbito de acción. Es el Ayuntamiento el encargado de velar el proceso de programación del suelo urbanizable, el cual puede estar promovido tanto por un particular como por la propia administración, pero sin olvidar que en el caso de los particulares, y partiendo de la competencia pública que a la acción urbanística otorga la LRAU, éstos no son más que adjudicatarios en la ejecución de un proceso público: la urbanización regulada por el programa. En el seno del mismo, aparece otra de las grandes novedades de la LRAU, el agente urbanizador, el cual es concebido como el ente encargado de llevar a cabo el desarrollo del programa mediante su selección, por el Ayuntamiento, en función a la propuesta de programación y desarrollo de suelo presentada y formalizada en un programa de actuación integrada.

En la tradicional legislación urbanística estatal, la clasificación y calificación del suelo urbanizable programado llevaba consigo una notoria revalorización urbanística de los terrenos. Como la inmensa mayoría de los propietarios no eran profesionales del urbanismo en su faceta más práctica, no solían desarrollar los planes por sí mismos, sino que buscaban empresarios del sector que les compraran sus parcelas con la finalidad de que éstos lideraran el proceso de transformación de los predios. Con más frecuencia de la habitual, y de la socialmente deseable, el precio que se le ofrecía a los propietarios por el terreno no satisfacía sus expectativas, con lo que la aparición de «disidentes» en el seno de las unidades de ejecución a desarrollar ejercía un efecto muy negativo en la definitiva ejecución del planeamiento. Ello tenía como consecuencias principales (MARTÍNEZ FERRER, 1999; 122127) la existencia de grandes cantidades de suelo sin urbanizar, la tardanza en gestionar las actuaciones urbanísticas, la presión sobre la administración para que aumentará los aprovechamientos urbanísticos o redujera las exigencias de la urbanización con la finalidad de que el incremento del lucro privado agilizara el proceso, así como la aparición de intermediarios dedicados a la adquisición de terrenos que luego vendían a terceros con el consiguiente aumento en la complejidad del ya de por si farragoso proceso.

Buscando reducir al máximo el número de agentes actuantes en el desarrollo de cada actuación, una solución habría sido la de articular un proceso mediante el cual fuera el dueño de los terrenos el encargado de ejecutar la finalidad urbanística de sus predios en el seno del plan, pero ¿es razonable exigirle todo eso al propietario?. Teniendo en cuenta que, en la inmensa mayoría de los casos éste no es más que un ciudadano con conocimientos justos en la materia urbanística, no parece demasiado razonable exigirle tanta participación en un procedimiento administrativo ya de por si muy complejo. La LRAU plantea una alternativa para dar solución al ancestral problema de la gestión del suelo urbanizable, la cual consiste en que la revalorización urbanística de los terrenos no se produzca como consecuencia de su planificación física, sino como consecuencia de su programación. Es decir, no habrá revalorización hasta que el ayuntamiento (o un particular en su representación) asuma el compromiso garantizado de promover, gestionar y financiar la gestión y urbanización de la unidad de ejecución correspondiente. Ese alguien es el urbanizador de 
la legislación valenciana, el cual tiene como obligaciones fundamentales la redacción de los proyectos técnicos que sean necesarios para el desarrollo de la urbanización, negociarlos con los propietarios afectados, elevar propuestas al Ayuntamiento para que éste los examine, realizar o contratar las obras de urbanización y financiar dichas obras; todo ello sin la necesidad de poseer en propiedad ni un solo metro del suelo a urbanizar. En definitiva, el urbanizador no es más que un agente económico que, en lícita competencia, es facultado por la administración para llevar a cabo la programación del suelo urbanizable, trasformándolo en urbanizado y obteniendo, como evidente pago por un servicio, bien una cuantía económica estipulada, o bien una cantidad determinada de suelo ya urbanizado. Así todos ganan, los propietarios, a cambio de satisfacer unas determinadas cuotas de urbanización, al cabo de un tiempo obtienen suelo urbanizado sin más complicación, mientras que una mercantil, o varias, ejecutan todos los trámites del proceso urbanizador, recibiendo una lógica retribución por ello.

El cambio de mentalidad es evidente, y las consecuencias de dicho proceso a la hora de acelerar todo lo concerniente a la gestión del suelo a urbanizar ha supuesto una reactivación de la actividad urbanística valenciana con unos niveles de eficacia muy superiores a los existentes antes de la entrada en vigor de la citada Ley (vid. MODREGO CABALLERO, 1997 y 2000; BLANC CLAVERO, 1997).

Todos estos hechos tienen implicaciones, más o menos directas, con la plasmación geográfica de toda actuación urbanística. Evidentemente, el cambio de filosofía a la hora de proceder a la clasificación del suelo, la mayor agilidad en su desarrollo, la apuesta por la urbanización como base de la edificación, así como la creación del agente urbanizador, implican una mayor facilidad para desarrollar en tiempo y forma la urbanización y edificación de sectores antes incultos, aumentando con ello la densidad del espacio urbano en detrimento de las periferias, extrarradios, zonas costeras, áreas de montaña, espacios singulares, ámbitos agrícolas e, incluso, territorios de manifiesta peligrosidad natural (lechos y márgenes inundables de redes fluviales). De la consideración geográfica del proceso depende la eficacia de dicha integración. Pasemos pues a analizar si la LRAU ha tenido en cuenta, además de la necesidad de mejorar la gestión urbanística del territorio a desarrollar urbanísticamente, las características geográficas del mismo como un factor muy importante a la hora de diseñar la ordenación urbanística municipal.

\subsection{Las consideraciones ambientales derivadas de su aplicación: la clasificación del sue- lo, las directrices definitorias de la estrategia a seguir y el carácter no vinculante de los estudios del medio físico}

El análisis de las determinaciones ambientales de los preceptos generales contenidos en la LRAU responde a la necesidad de valorar la consideración que hace la misma del territorio como algo más que un mero soporte de la actividad urbanística. Con la finalidad de sistematizar dicho análisis, no es este el lugar de recoger todas y cada una de las disposiciones que contienen o regulan aspectos relacionados con el medio ambiente municipal, ya que ello obligaría estudiar cuestiones tales como la determinación de estándares relacionados con los equipamientos, dotaciones, espacios libres y aspectos de similar trascendencia urbanística. Sin que ello lleve implícito ningún tipo de desinterés por la importancia de dicho tratamiento dentro de todo análisis urbanístico, vamos ha tratar de valorar cómo se contempla la realidad ambiental municipal en los fines y objetivos establecidos por la Ley, además de si se establece un, a nuestro juicio y desde un punto de vista eminentemente geo- 
gráfico, lógico proceso de asignación de usos urbanísticos al territorio acordes con su dinámica natural y potencialidad territorial ${ }^{5}$.

\subsubsection{La LRAU y sus principios rectores: la asunción del «Orden Constitucional ambiental»}

Las líneas maestras de la filosofía de la LRAU vienen recogidas en el punto tercero de su Preámbulo, donde se consagra al planeamiento, en cuanto a decisión pública de racionalización del uso del territorio, mediante la apuesta por un plan rico en análisis y previsiones. Asimismo, la letra $g$ del artículo primero de la citada Ley establece que, dentro de las facultades urbanísticas inherentes a dicha práctica en el territorio valenciano, está «la protección del patrimonio arqueológico, del ambiente y del paisaje, urbano o rústico, conforme a la percepción y vivencia colectiva de los mismos». La importancia de estas dos afirmaciones es básica, ya que parecen abrir la puerta a un nuevo procedimiento mediante el cual las determinaciones del planeamiento descansen sobre estudios en los que el análisis de la dinámica del medio se convierta en parte fundamental del proceso. Por desgracia, el estudio de la forma en la que dicho principio general se integra en las disposiciones de la Ley, así como en su desarrollo reglamentario, revela cómo lo enunciado no queda en más que en una declaración de principios de aplicabilidad totalmente dependiente a la discrecionalidad municipal y autonómica. La concordancia inherente a la letra $g$ del artículo primero nos remite a una serie de preceptos que tratan de resumir la vinculación ambiental de la práctica urbanística valenciana:

Artículo 2.2. «Las potestades urbanísticas, y en particular, la de planeamiento, se ejercerá con el fin de asegurar un entorno ambiental, rural o urbano, adecuado al desarrollo de la persona, cuya calidad de vida y su derecho a disfrutar de una vivienda digna, así como de los espacios y construcciones constitutivos del patrimonio cultural colectivo, determinará todas las decisiones públicas respecto a la utilización de los terrenos a las características de las construcciones».

Artículo 12.E. «Planes Especiales, que - en desarrollo, complemento o, incluso, modificación del planeamiento general y parcial - cumplen cualquiera de los siguientes cometidos: (...), definir y proteger las infraestructuras o vías de comunicación, el paisaje o el medio natural, $(\ldots) »^{6}$.

$5 \quad \mathrm{Al}$ respecto de ello, se ha de reseñar que dos de los aspectos de notables connotaciones ambientales más importantes de la LRAU vienen recogidos en normas externas a la misma pero concordantes con ella. Así, la regulación del suelo no urbanizable tiene un carácter positivo en la LRAU, recogiéndose éste en una norma anterior incluso a la propia LRAU (1992, reformada en 1997). Además de ella, la COPUT ha normativizado, por órdenes del Conseller (1999 y 2000), el uso y adaptación de los instrumentos de planeamiento general y parcial a una serie de cartografías temáticas en las que, a nivel regional y sobre la base de las divisiones del Mapa Topográfico de España a escala 1:50.000, se caracterizan una serie de procesos naturales de obligada observancia por el planificador municipal (riesgo de inundación, desprendimientos, deslizamientos, vulnerabilidad a la contaminación de las aguas subterráneas, accesibilidad potencial a los recursos hídricos, erosión actual y potencial del territorio, entre otros). Además, ni que decir tiene que también es importante al efecto el sometimiento de los instrumentos de planeamiento al procedimiento de Evaluación de Impacto ambiental. Así, aunque foráneos normativamente a la LRAU, ésta recoge las bases de dicha normativa externa, coetánea e inherente a la actual práctica urbanística valenciana, en su articulado, con lo que el carácter geográfico de los fundamentos operativos que auspician la LSNU-CV y las cartografías temáticas de la COPUT es consustancial a los propios principios ambientales de la LRAU a valorar a continuación.

6 Su función, determinaciones y documentación quedan regulados del artículo 86 a 91 del RP-CV. 
Artículo 12.F. «Catálogos de Bienes y Espacios Protegidos, que identifican y determinan el régimen de preservación y respeto para las construcciones, conjuntos, jardines y otro tipo de espacios, cuya alteración se someta a requisitos restrictivos, acordes con la especial valoración restrictiva que merezcan dichos bienes» Artículo 25. «Los Catálogos de Bienes y Espacios Protegidos formalizarán las políticas públicas de conservación, rehabilitación o protección de los bienes inmuebles o de los espacios de interés. A tal fin, se seleccionarán los que se consideren de interés artístico, histórico, paleontológico, etnológico, arquitectónico o botánico y los que integren un ambiente característico tradicional, así como los que se pretenda conservar por su representatividad del acervo cultural o por razones paisajísticas» ${ }^{7}$. Artículo 95. Órdenes de adaptación al ambiente. «Los planes pueden disponer la obligatoriedad de ejecutar obras de adaptación al ambiente de edificios. (...). Estas órdenes se deberán referir a elementos ornamentales y secundarios del inmueble, pretender la restitución de su aspecto originario o coadyuvar a su mejor conservación» ${ }^{8}$.

Puede apreciarse que, al igual que en la legislación estatal precedente, los preceptos que la LRAU considera de vinculación con el medio ambiente municipal se limitan al mero establecimiento de ámbitos, espacios o inmuebles a proteger por la concurrencia en los mismos de una serie de valores en los que calidad y representatividad son la nota predominante. Los Planes Espaciales siguen considerándose como la panacea de la protección ambiental del municipio, así como los catálogos mantienen su concepción documental de registro de todo lo municipal que merezca dicha protección al margen de la que ya implica la delimitación de suelo no urbanizable de especial protección. A su vez, y todavía dentro de la letra g del artículo primero de la LRAU, en el cual se faculta el contenido ambiental de dicha Ley, y al margen de la obligada remisión a la LSNU-CV, se considera una concordancia ajena a las disposiciones de dicho texto, la cual remite al análisis de lo establecido en al Capítulo IV de la Ley 6/1989, de 7 de julio, de Ordenación del Territorio de la Comunidad Valenciana, en cuyas secciones Primera, «El patrimonio rural de suelo» y Segunda «Del medio ambiente rural», se establecen una serie de consideraciones ambientales de finalidad amparadas por la LRAU, entre las que destacan las siguientes'

Artículo 63. «El patrimonio rural de suelo se compone del espacio físico que debe detraerse de la acción urbanizadora, con sus elementos y accidentes geográficos, las masas vegetales, plantaciones de interés comunitario, conjuntos de yacimientos arqueológicos e históricos, mineralógicos y de hidrocarburos, y espacios naturales merecedores de protección o conservación» ${ }^{10}$.

7 Su función, determinaciones y documentación quedan regulados del artículo 92 a 98 del RP-CV.

8 En este sentido, el artículo 3.1 de la LRAU, a la hora de sistematizar las normas de aplicación directa, alude a la necesaria adaptación de las construcciones al medio ambiente, tal y como versa el artículo 138 del TR92, siguiendo la línea del mismo al no establecer más aspectos al respecto, con lo que, a todas luces, la falta de precisión de lo normativizado es evidente.

9 El resto de secciones del capítulo aluden al paisaje (3), a la protección del suelo en función a su aptitud (el artículo 77 aboga por la máxima explotación de las tierras fértiles, impidiendo sobre ellas nuevos asentamientos urbanos o su expansión injustificada), de los recursos hídricos y la protección de su calidad (5), de los vertidos y los residuos sólidos (6), de los equipamientos supramunicipales (7) y de las infraestructuras (8).

10 Ampliado por el contenido de los artículos 1 a 9 de la LSNU-CV y 9 de la LS98, con las salvedades impuestas en el DL00. 
Artículo 66. «No se permitirá ninguna actuación que menoscabe las características de las zonas húmedas ni la extracción masiva de elementos minerales que contengan, todo ello al amparo de lo establecido en el ordenamiento jurídico» ${ }^{11}$. Artículo 68.1. «Todos los cauces públicos y privados deben mantenerse expeditos. No se autorizará su aterramiento o reducción sin que exista un proyecto debidamente aprobado por el órgano competente que plantee solución alternativa que garantice el discurrir normal de las aguas» ${ }^{12}$.

Artículo 69. «Se prohíbe toda edificación sobre terrenos provenientes de cauces y hasta 20 metros de su arista exterior».

Artículo 70. «Las plantaciones que se lleven a cabo en los mismos serán de escasa entidad y en ningún caso se autorizarán cultivos arbóreos, o de otra naturaleza que impidan el curso de las aguas, hasta el límite de su ribera».

Con la concordancia de esta serie de disposiciones propias de la vigente legislación de ordenación del territorio de la Comunidad Valenciana, la LRAU parece hacer suyos los preceptos taxativamente restrictivos que dicha norma establece sobre ámbitos de tan notoria y evidente peligrosidad como son los cauces fluviales. El problema de ello estriba en la siempre carente presencia de un criterio eminentemente geográfico que delimite estrictamente lo qué es realmente constitutivo de una determinada red hidrográfica, para con posterioridad zonificar ámbitos de riesgo en función a la dinámica geomorfológica inherente a cada una de sus partes. Los principios de prohibir construcciones y plantaciones en cauces y riberas son tan loables como probablemente eficaces, pero la existencia de los mismos no implica, muy a pesar de lo evidentemente lógico, la aplicabilidad de estas restricciones sobre ámbitos que, fuera del ordenamiento urbanístico, son sectorialmente protegidos y, en el seno del mismo, han de ser automáticamente consignados como bienes de dominio público no municipal y, en virtud de ello, han de contar, además, con una especial protección por parte de la legislación urbanística.

Si importantes son las facultades urbanísticas que la Ley se atribuye en el punto primero de su primer artículo, no lo son menos los fines que para ello estipula en el segundo de los aparatados existentes en el mismo. Para ello la Ley valenciana nos remite a una de sus novedades operativas y jurídicas más sobresalientes, definiendo como fines propios de la actividad urbanística y principios rectores de su desarrollo los enunciados en los artículos 45, 46 y 47 de la Constitución Española. Estos principios rectores, o directrices constitucionales de la política social y económica del país, conforman el «Orden Constitucional Ambiental» (MARTÍNEZ FERRER, 1999; 205-208) fundamentado en el denominado desarrollo sostenible o ecodesarrollo, el cual debe compaginar la protección del medio ambiente con el progreso económico y social en razón de lo establecido el artículo 40.1 de la Carta Magna española. A este respecto, cabe reproducir literalmente los citados artículos constitucionales dada la novedad que supone que una legislación autonómica encargada de desarrollar la normativa que, constitucionalmente, compete a la Generalitat Valenciana en

11 Artículo 111 del Texto Refundido de la Ley de Aguas aprobado por Real Decreto Legislativo 1/2001, de 20 de julio; así como artículos 275-283 del RD 849/1986, de 11 de abril, por el que se aprueba el Reglamento del Dominio Público Hidráulico que desarrolla los títulos Preliminar, I, IV, V, VI y VII del Texto Refundido de la Ley de Aguas.

12 Artículos 2-8 del Texto Refundido de la Ley de Aguas, así como artículos 4-11 del RD 849/1986, de 11 de abril, por el que se aprueba el Reglamento del Dominio Público Hidráulico que desarrolla los títulos Preliminar, I, IV, V, VI y VII de la Ley 29/1985. 
materia de ordenación urbanística del territorio, tome como fines propios de la actividad derivada del ejercicio de dicha competencia los principios constitucionales de mayores implicaciones en la política ambiental del Estado Español.

Artículo 45 CE: «1. Todos tienen derecho a disfrutar de un medio ambiente adecuado para el desarrollo de las personas, así como el deber de conservarlo. 2. Los poderes públicos velarán por la utilización racional de todos los recursos naturales, con el fin de proteger y mejorar la calidad de vida y defender y restaurar el medio ambiente, apoyándose en la indispensable solidaridad colectiva. Para quienes violen lo dispuesto en el apartado anterior, en los términos en los que la Ley fije se establecerán sanciones penales o, en su caso, administrativas, así como la obligación de reparar el daño causado ${ }^{13} \gg$.

Artículo 46 CE: «Los poderes públicos garantizarán la conservación y promoverán el enriquecimiento del patrimonio histórico, cultural y artístico de los pueblos de España y los bienes que lo integran, cualquiera que sea su régimen jurídico y su titularidad. La Ley penal sancionará los atentados contra este patrimonio».

Artículo 47 CE: «Todos los españoles tienen derecho a disfrutar de una vivienda digna y adecuada. Los poderes públicos promoverán las condiciones necesarias y establecerán las normas pertinentes para hacer efectivo este derecho, regulando la utilización del suelo de acuerdo con el interés general para impedir la especulación».

La LRAU presenta así uno de sus preceptos filosóficos más destacados y novedosos, al atribuir los fines propios de la actividad que regula a parte de los principios rectores de la política social y económica que han de velar para todo el Estado. Con ello se consigue una más que destacada relación entre la naturaleza de la norma y la madre de todas ellas, pero sin que ello implique la inclusión de prácticas ambientales novedosas en su seno que puedan justificar un tratamiento del territorio acorde con los principios que la Constitución, en su esencia, trata de defender.

2.2.2. Los instrumentos de ordenación y su contenido documental: la persistencia del carácter no vinculante del conocimiento geográfico del territorio

Desde un punto de vista estrictamente literal, los aspectos enunciados con anterioridad son los más puramente ambientales que en esencia define la LRAU en cuanto a sus principios de actuación territorial sobre los que trata de legislar. Ahora bien, geográficamente, la práctica urbanística lleva asociada el desarrollo de una serie de instrumentos apoyados en una documentación cuyo cometido final es el de la propia ordenación urbanística de todo ámbito municipal adscrito al territorio valenciano. Partiendo de la ya enunciada distinción entre ordenación estructural y pormenorizada que ha de contener todo plan general, en el seno de la primera se encuentran una serie de aspectos cuya regulación es de capital impor-

13 Por desgracia, y lejos de la filosofía del espíritu de la norma, la posibilidad de penalizar infracciones medioambientales mediante el pago de un determinado «canon» o penalización ha supuesto la asunción, no de la idea punitiva de «quien contamina o daña el medio ambiente ha de ser penalizado por ello», sino la de que «quien puede pagar y tiene medios para defenderse, está facultado a contaminar y agredir al medio ambiente». 
tancia a la hora de establecer el tratamiento que al medio municipal otorga la norma urbanística valenciana.

El proceso de ocupación territorial más importante que lleva a cabo el planeamiento viene amparado por la técnica de la clasificación de suelo. Ésta es propia de la ordenación estructural de todo municipio, estando definidas las manchas por criterios que han de ser perfectamente estipulados por la Ley, ya que en base a ellos se produce la asignación a los predios de un determinado régimen urbanístico que afecta al fin de cada uno de ellos en función a su ámbito de adscripción. De la adopción, o no, de criterios geográficos para ello depende, muy directamente, la idoneidad territorial de la definitiva clasificación del suelo ${ }^{14}$.

Las tres clases de suelo en las que todo el territorio municipal ha de estar dividido por el planeamiento son no urbanizable, urbano y urbanizable. La delimitación del suelo no urbanizable es, por primera vez y en notoria anticipación a las legislaciones urbanísticas tanto estatales como autonómicas, positiva, estando definida por un pionero marco legal específico al efecto; mientras que los suelos urbanos y urbanizables son clasificados por la tipología de actuaciones que en ellos pueden llevarse a cabo al amparo de la LRAU, obviándose, por primera vez en lo concerniente a la delimitación del suelo urbano, criterios de consolidación en su delimitación. Pero es importante destacar que, a la hora de establecer los criterios generales que han de regir la clasificación de los predios en urbanos o urbanizables, la LRAU establece:

Artículo 8.4. «El Plan clasificará como suelo urbano y urbanizable los terrenos que, por convenir a su modelo territorial, se pretendan mantener o incorporar dentro del proceso de urbanización,...»

Así, al margen de las estimaciones que acerca de la gestión determinan la clasificación del suelo en urbano y urbanizable, la Ley establece que ello también depende del modelo territorial diseñado por el municipio; con lo que la asignación de predios a urbanizar puede ajustarse a una discreccionalidad hoy, desgraciadamente, no valida en virtud a lo dispuesto en el DL00.

Por tanto, el acto de clasificar suelo es, a todas luces, el procedimiento de mayores implicaciones geográficas de la práctica urbanística, ya que es éste el que determina la ocupación, o no, de ámbitos en detrimento de su conservación. Es ahí donde es interesante reflexionar sobre la gran paradoja del urbanismo valenciano, y por extensión del sistema urbanístico español, en tanto y cuanto éste apoya la asignación de usos al territorio sobre la base de un método escasamente fundamentado en la dinámica territorial imperante.

Ello es así porque el marco legal no articula la necesidad de llevar a cabo un completo y riguroso estudio de la dinámica territorial municipal como paso previo, básico y fundamental, a la evaluación de la aptitud de los predios para su desarrollo urbanístico. Se cree suficiente establecer una serie de criterios de naturaleza positiva en la delimitación del suelo no urbanizable (tal y como establece la LSNU-CV y la LS98), lo cual no es poco avance si se

14 Recordar, al efecto de la clasificación del suelo, que, por Sentencia del Tribunal Constitucional 61/1997, la facultad de establecer estos criterios clasificativos es estatal y están recogidos en la LS98 y sus posteriores modificaciones. Salvo en la necesaria supresión del no urbanizable común a la que se ha de adaptar al LSNU-CV, el resto de contenidos de la LRAU en la materia no entran en colisión con lo emanado de la normativa estatal. 
atiende al procedimiento que se seguía con anterioridad. En relación a ello, la LRAU establece, como criterio estructural y básico, la necesidad de definir unas Directrices definitorias de la estrategia de evolución urbana y de ocupación del territorio ${ }^{15}$ las cuales tienen como finalidad fundamental:

«Establecer criterios que justifiquen la adecuación de las determinaciones de los planes a la política territorial de la Comunidad Valenciana y, en particular de su adecuación a los Planes de Acción Territorial, así como su coordinación con las distintas políticas sectoriales. Identificar y establecer los objetivos fundamentales del Plan General en coherencia con la política urbanística municipal, diferenciándolos de sus previsiones instrumentales susceptibles de ser modificadas con mejoras alternativas que persigan la misma finalidad».

De esto se desprende que dichas directrices parecen estar en posesión de la función potestativa de determinar, como su propio nombre indica, la estrategia urbanística a seguir por el municipio, la cual ha de estar correctamente fundamentada en una serie de criterios territoriales acordes con la política emanada desde la Generalitat en sus distintas manifestaciones. Ahora bien, ¿cómo se elaboran y en qué han de basarse dichas directrices? El RP$\mathrm{CV}$ lo establece con una claridad meridiana, recogiendo una serie de aspectos que parecen ir en contra de la filosofía que define la propia esencia de las directrices. En ese sentido, sobre el contenido de las mismas expresa:

Artículo 7.1.a. «Señalar las oportunidades, diagnosticar los principales problemas y formular los objetivos prioritarios de la ordenación urbanística y territorial. En particular, dejarán constancia de la finalidad perseguida con la clasificación del suelo como no urbanizable o urbanizable (...). 2. Las previsiones contenidas en las directrices definitorias de la estrategia de evolución urbana y de ocupación del territorio, son determinaciones esenciales con vocación de permanencia durante la vigencia del plan (...). 3. Las directrices definitorias de la estrategia de evolución urbana y de ocupación del territorio se formularán de forma concreta y precisa evitando sustanciarse en meras declaraciones de principio o postulados teóricos. Su redacción será escueta y obviará argumentos descriptivos y justificativos».

La simple lectura de lo trascrito puede llevar a cualquiera a la más lógica sinrazón. ¿Cómo puede defenderse la elaboración de un documento que ha de «diagnosticar los principales problemas y formular los objetivos prioritarios de la ordenación urbanística y territorial» de una forma «concreta y precisa evitando sustanciarse en meras declaraciones de principio o postulados teóricos» realizándolo mediante una «redacción escueta y obviando argumentos descriptivos y justificativos»? La paradoja y el absurdo es del todo evidente. Independientemente de la ya triste no mención de ningún tipo de criterio ambiental a la hora de elaborar dichas directrices, las cuales parecen estar concebidas como un instrumento con la virtud de justificar el no urbanizable y las necesidades de urbanizable de acuerdo con los deseos expansionistas del consistorio municipal, ¿alguien puede explicar cómo elaborar una estrategia coherente de ocupación del territorio sin realizar un estudio previo que posea un mínimo de seriedad y entidad? Independientemente de que las directrices hayan de con-

15 Artículos 4, párrafo segundo, 16, 17.1 y 37 de la LRAU. 
formarse como un documento síntesis, su fundamento ha de sustentarse en un análisis que evite que éstas se «sustancien en meras declaraciones de principio o postulados teóricos», lo cual no está, en absoluto, regulado en el RP-CV, con lo que la gran trascendencia que la novedad del instrumento-documento podía poseer para la consideración de la dinámica ambiental en el diseño de la trama urbana cae por su propio peso a la mera conciencia del planificador municipal. Además, más gravedad tiene ello si se tiene en cuenta el carácter de eficacia normativa que dicho instrumento, integrante de la ordenación estructural del Plan General, posee en su parte documental, ya que sus determinaciones han de ser recogidas en la necesaria justificación de la opción de desarrollo urbano escogida.

Además de la clasificación de suelo y del establecimiento de las directrices definitorias de la estrategia de ocupación urbana del territorio, la ordenación estructural de todo plan general también ha de contener el tratamiento de los bienes de dominio público no municipal, estableciendo las áreas de protección y servidumbre que le sean propias conforme a su legislación reguladora, no pudiendo, en ningún caso, establecer disposiciones contradictorias a lo establecido por dicha normativa ${ }^{16}$.

En lo concerniente a los estudios integrantes de todo plan general, se parte de la ya comentada premisa básica de que todo plan tiene la obligación de establecer los criterios que han de fundamentar su ocupación urbanística del territorio, (incluido ello en las directrices definitorias de la misma) lo cual habría de articularse en base a un estudio concienzudo de la dinámica territorial municipal. La realidad que muestra la inexistencia de ello puede apreciarse a la perfección en el análisis de la documentación e informes que todo plan general ha de contener. La LRAU establece, en su artículo 27, un sistema dual en su contenido documental, donde la diferencia más importante estriba en la eficacia normativa de la misma. A estos efectos, el artículo 45 del RP-CV sistematiza dicha documentación de la siguiente manera:

1. Parte sin eficacia normativa: documentos de información (memoria y planos) y memoria justificativa.

2. Parte con eficacia normativa: directrices definitorias de la estrategia de evolución urbana y de ocupación del territorio; normas urbanísticas; fichas de planeamiento; catálogos de bienes y espacios protegidos y planos de ordenación.

Al igual que en el marco estatal, el planeamiento urbanístico valenciano no da eficacia normativa a los documentos de información urbanística, dentro de los cuales se inserta plenamente el estudio de las condiciones geográficas del medio municipal, las cuales comprenden, según el artículo 47 del RP-CV, el análisis de:

1. Las características naturales del territorio: geológicas, topográficas, climáticas, hidrológicas y otras.

2. El aprovechamiento de que sea susceptible, desde el punto de vista agrícola, forestal, ganadero, cinegético, minero y otros.

3. Los usos actuales del suelo.

4. La diferente aptitud de los terrenos para su utilización urbana y los riesgos que pudiera dificultar la misma.

5. Los valores paisajísticos, ecológicos, urbanísticos e históricos y artísticos existentes en el ámbito del Plan.

16 Artículo 17.1.F de la LRAU y 18 del RP-CV. 
6. Las características de la población, sus condiciones económicas y sociales y las previsiones de evolución demográfica.

Los contenidos establecidos por el reglamento para la elaboración de la citada memoria, mejorados en aspectos puntuales, son ya de por si suficientes para llevar a cabo un riguroso estudio del medio municipal, pudiéndose extraer del mismo los argumentos necesarios para elaborar unas directrices y estrategias de ocupación urbana del territorio acordes con su dinámica real, no con la derivada de la reflexión política sobre las necesidades de expansión del núcleo urbano tradicional. La eficacia no normativa de esta documentación escapa a la lógica, ya que le da un carácter eminentemente residual a la información territorial a obtener de dichos estudios, la cual completada con la información urbanística a elaborar del territorio ordenado por el planeamiento vigente con anterioridad, (artículo 48 del RP-CV), debería sustentar la eficacia normativa de las directrices incluidas en la ordenación estructural. La novedad de que el punto d del artículo 47 del RP-CV sí contemple la aptitud de los terrenos para su desarrollo urbano, así «como los riesgos que pudieran dificultar la misma», constituye un aspecto muy novedoso en los procesos a consignar por los documentos de información urbanística pero, tal y como se evidencia, su plena inserción en un apartado sin eficacia normativa puede desvirtuar, y de hecho desvirtúa, sus determinaciones.

El gran problema se encuentra en la diferencia que el planeamiento establece entre la eficacia normativa de la documentación que ha de fundamentarlo. A nadie se le ocurre poner en duda la necesidad de que las normas urbanísticas sean de obligado cumplimiento, ya que las mismas se establecen con la finalidad de generar una obligación legal en cuento a su aplicación. ¿Por qué el legislador valenciano, al dar un paso importante dotando al planeamiento de la necesidad de justificar el modelo de desarrollo elegido en unas directrices, no refuerza esa filosofía estableciendo la obligatoriedad de estudiar concienzudamente el medio municipal para establecer la citada estrategia? A todas luces parece tan lógico que hasta duele la incongruencia, en ese sentido, del sistema. La información geográfica y urbanística debería ser el primer documento de un Plan General, elaborado por profesionales competentes en la materia, presentando unos contenidos mínimos legalmente estipulados y cuya finalidad habría de ser la de determinar la aptitud del territorio para su transformación urbana en función a la dinámica natural propia del mismo.

La misma jerarquía documental se mantiene en el resto de instrumentos de ordenación vigentes en el sistema de planeamiento que establece la legislación valenciana. Los planes parciales también cuentan con los dos bloques documentales bien diferenciados por la eficacia normativa de la información emanada de ellos ${ }^{17}$. Fijémonos en la importancia que podrían tener las memorias de información geográfica en estudios de planeamiento parcial, las cuales podrían gravitar como auténticos documentos cuya aproximación escalar a la realidad territorial permitiría una más que extraordinaria y definitiva caracterización física de los ámbitos a ordenar pormenorizadamente. Una correcta jerarquía documental entre el planeamiento general y parcial podría establecer un sistema de análisis territorial como el que se propone:

- El Plan General establece la clasificación y sectorización del suelo en función a un estudio general de su aptitud física, regulado en su memoria de información urbanística y vinculante a los efectos de establecer las directrices de ocupación a seguir.

17 Artículo 27 de la LRAU y 64 del RP-CV. 
- Con posterioridad, el planeamiento parcial encargado de desarrollar la ordenación pormenorizada de cada sector, realizará, mediante su respectiva memoria de información, su propio estudio territorial del ámbito de planeamiento, gracias al cual estará en disposición de llevar a cabo una ocupación pormenorizada del medio extraordinariamente adaptada a la realidad observada, ya que la escala de su aproximación geográfica es más que idónea para detectar cualquier tipo de proceso o aspecto que haya de tenerse en cuenta en el diseño detallado de la definitiva ocupación.

Con un ejemplo se puede entender a la perfección el sistema que se propone. Supongamos la caracterización de la red fluvial que se realizaría en uno de los apartados de la memoria de información vinculante de nuestro supuesto Plan General. La escala de aproximación de la misma determinaría una red fluvial (entre 1:25.000 y 1:10.000) muy aproximada pero que, puntualmente podría necesitar de un más detallado análisis. Así, las conclusiones del estudio de aptitud derivarían en la definición de la clasificación y calificación del suelo, en cuyo desarrollo pormenorizado se habría de observar la existencia de dicha red y de la escorrentía derivada, resolviendo su confrontación con la urbanización en forma y modo que ello no generara riesgo tras la ocupación. Pues bien, el sistema que se propone haría obligatorio que el planeamiento parcial llevara a cabo, en su memoria de información urbanística, un estudio más detallado de dicha red, delimitando su peligrosidad exacta, su configuración geomorfológica, así como todos los aspectos y procesos que tengan que ser considerados en el diseño de la red urbana proyectada por el citado instrumento de desarrollo, todo ello completado con las cartografías de corte ambiental definidas por Consellería mediante las órdenes de los años 1999 y 2000.

\section{Consideraciones finales: el necesario carácter vinculante de las memorias de infor- mación geográfica}

Todo lo indicado ofrece una idea general acerca de que la legislación valenciana, a pesar de introducir novedades interesantes con respecto al sistema estatal imperante antes de su promulgación, atendiendo a la consideración que ella hace del territorio como paso previo al diseño del desarrollo urbano, no presenta novedades estructurales de peso que le hagan merecedora de una mayor distinción a este respecto. Las enormes innovaciones en materia de gestión y agilización de trámites urbanísticos se diluyen lentamente en una ordenación nuevamente asentada en la discrecionalidad municipal y en la delimitación de suelo no urbanizable de especial protección como único precepto ambientalmente sostenible de su sistema urbanístico (a pesar que de ello no se le deba achacar toda la culpa al legislador valenciano). A grandes rasgos, sumando la entrada del procedimiento de evaluación de impacto ambiental del planeamiento, así como la obligada observancia de cartografías temáticas de interés ambiental, se está ante más de lo mismo.

A pesar de que los planes aprobados al amparo de la LRAU han mejorado ostensiblamente las tradicionalmente paupérrimas, inconexas y enciclopédicas memorias de información, éstas todavía siguen presentando un carácter meramente recopilatorio sin establecer ningún tipo de conexión aplicada entre la geografía municipal y la propuesta urbanística. Desde estas líneas se apuesta enérgicamente por la definición de un modelo de planeamiento en el que las memorias de información tengan el carácter vinculante que el mero ejercicio racional impone. El término ordenación hace referencia a la correcta ubicación de una serie de elementos y hechos en función a un contexto determinado. El contexto es la soste- 
nibilidad por la que la legislación urbanística valenciana aboga; los elementos en su conjunción forman el medio geográfico al que es necesario dar un orden en notoria y acertada respuesta a la paulatina degradación de nuestros ecosistemas, medio rural y, cómo no, a la génesis de cada vez más ámbitos de riesgo natural.

Partiendo de una coherente jerarquía normativa e instrumental entre los planes y la documentación emanada de los mismos, sería interesante que la legislación urbanística valenciana articulara un sistema de planeamiento que otorgara a las memorias de información geográfica un carácter vinculante y determinante en el diseño de las directrices definitorias de la estrategia de ocupación urbana del territorio que, como parte integrante de la ordenación estructural, ya sí estarían en notoria disposición de determinar una estrategia de ocupación del medio debidamente fundamentada en un conocimiento riguroso del mismo. Tras ello, la clasificación y calificación del suelo encontraría en el plan general toda su expresión justificativa y geográficamente documentada, ya que no se ha de olvidar que la protección del suelo por parte del planificador municipal (clasificación de no urbanizable protegido como figura única) ha de ir siempre acompañada de una objetiva justificación.

Se establecería así un marco operativo para cuyo funcionamiento eficaz únicamente habría de modificarse la regulación actual de la norma referente a la eficacia normativa de los instrumentos de planeamiento. Las nuevas memorias, y las directrices derivadas, así como la clasificación y sectorización del suelo establecida al efecto, serían sometidas a exposición pública y analizándose y aprobándose definitivamente por la autoridad autonómica en un nuevo organismo o departamento creado al efecto. Éste habría de estar integrado por técnicos territoriales donde profesionales de la geografía mucho podrían aportar, ya que su finalidad fundamental sería evaluar la calidad y validez de los estudios, así como su relación con la estrategia territorial supramunicipal y autonómica, además de con el resto de normativa de acción sectorial vigente. De la competencia de dicho organismo depende en gran parte el éxito de la reforma planteada, asegurándose con ello la autoridad autonómica dos aspectos fundamentales: de un lado, otorgaría un verdadero carácter territorial a una práctica, la urbanística, todavía hoy carente de una real vinculación con la dinámica del medio que tradicionalmente ha «ordenado»; por otra parte, también se aseguraría el establecimiento de un eficaz modelo de desarrollo regional propio y de calidad, sustentando el mismo en la completa y veraz observancia del medio municipal en la asignación de usos urbanísticos al mismo.

Así, carece de sentido otorgar a procedimientos externos a la práctica urbanística (evaluación de impacto ambiental, protección especial del suelo por su afección a la legislación ambiental vigente y obligada observancia de cartografías temáticas) el poder regulador del proceso de ocupación urbana del territorio, más si cabe si se atiende a que una eficaz y adecuada concepción de los principios que han de regir dicha ocupación otorgan a ésta una sobresaliente capacidad operativa en la materia.

\section{Bibliografía}

BLANC CLAVERO, F. (1997): «Los efectos de la LRAU sobre la actividad urbanizadora: causas y consecuencias de una transformación». en Ciudad y Territorio. Estudios Territoriales $\mathrm{n}^{\circ}$. 112. Ministerio de Fomento. Madrid, pp. 257-294.

GÓMEZ OREA, D. (1994): Ordenación del territorio. Una aproximación desde el medio físico. I.T.G.E. y Editorial Agrícola Española S.A. Madrid, 238 pp. 
MARTÍNEZ FERRER, S. V. (1999): Legislación urbanística valenciana. Ed. Tirant lo Blanc. Valencia, p. 783.

MENÉNDEZ REXACH, A. (1999): «Ordenación del territorio y medio ambiente: problemas de articulación» en MELGOSA ARCOS, F. J. (coord.): Estudios de derecho y gestión Ambiental I. Fundación Cultural Santa Teresa. Ávila, pp. 61-77.

MELÓN MUÑOZ, A. (1999): Urbanismo. Francis Lefebvre. Madrid, 1.327 pp.

MIGUEL BELENGUER, J. L. (1997): «La iniciativa privada y la ley reguladora de la actividad urbanística» en Ciudad y Territorio. Estudios Territoriales $\mathrm{n}^{\circ}$. 112. Ministerio de Fomento. Madrid, pp. 295-310.

MINISTERIO DE OBRAS PÚBLICAS Y TRANSPORTES (1991): Directrices ambientales para la planificación y gestión de asentamientos. Programa de las Naciones Unidas para el Medio Ambiente. Centro de las Naciones Unidas para los Asentamientos Humanos. Madrid, $477 \mathrm{pp}$.

MONDREGO CABALLERO, F. (1997): «La liberalización del urbanismo. La experiencia valenciana». en Ciudad y Territorio. Estudios Territoriales $\mathrm{n}^{\circ}$. 112. Ministerio de Fomento. Madrid, pp. 251-254.

MONDREGO CABALLERO, F. (2000): «Cuarenta meses de aplicación de la Ley Reguladora de la Actividad Urbanística en la Comunidad Valenciana» en Ciudad y Territorio. Estudios Territoriales $\mathrm{n}^{\mathrm{o}}$. 123. Ministerio de Fomento. Madrid, pp. 11-27.

MOYA GONZÁLEZ, L. (edt.) (1996): La práctica del planeamiento urbanístico. Editorial Síntesis. Madrid, 278 pp.

OLCINA CANTOS, J. y RICO AMORÓS, A. (1998): «Los riesgos climáticos en la ordenación urbana» en Arquitectura Técnica nº $^{\circ}$ 33. Madrid, pp. 37-44.

OLCINA CANTOS, J. (2002): «Riesgos naturales y ordenación territorial» en AYALACARCEDO, F. J. y OLCINA CANTOS, J. (coords.): Riesgos naturales. Arial Ciencia. Barcelona, pp. 1235-1307.

PAREJO ALFONSO, L. (1996): «Apuntes para una interpretación del sistema legal urbanístico español en clave histórica» en Ciudad y Territorio. Estudios Territoriales. Siglo y medio de urbanismo en España. no. 107-108. Ministerio de Fomento. Madrid, pp. 127-148.

RAMÓN FERNÁNDEZ, T. (1999): Manual de Derecho Urbanístico. Editorial El Consultor de los Ayuntamientos y los Juzgados, S.A. 14ª Edición. Madrid, 286 pp.

SÁNCHEZ GOYANES, E. (1998): «La potestad municipal de clasificación del suelo en la nueva legislación estatal. La energética rectificación rectificada a tiempo» en $\mathrm{El}$ Consultor de los Ayuntamiento y de los Juzgados, $\mathrm{n}^{\circ}$. 6769. Madrid, pp. 1030-1046.

SÁNCHEZ GOYANES, E. (1999): «Técnicas urbanísticas de protección ambiental» en MELGOSA ARCOS, F. J. (coord.): Estudios de derecho y gestión Ambiental I. Fundación Cultural Santa Teresa. Ávila, pp. 79-116.

SÁNCHEZ GOYANES, E. (2000): «El Real Decreto-Ley 4/2000, de 23 de junio, de medidas urgentes de liberalización en el sector inmobiliario. Sus efectos sobre la legislación urbanística estatal y autonómica y sobre el planeamiento de los municipios» en El Consultor de los Ayuntamientos nº. 14. Madrid, 2.934-2.411 pp.

VERA REBOLLO, J. F. (1989): «Protección de cauces en el planeamiento urbanístico y la ordenación del territorio: estado de la cuestión a través del caso alicantino» en GIL OLCINA, A. y MORALES GIL, A. (edits.): Avenidas fluviales e inundaciones en la cuenca del Mediterráneo. Instituto Universitario de Geografía, Universidad de Alicante y Caja de Ahorros del Mediterráneo. Alicante, pp. 565-574. 